\title{
O ESTUDO DOS MOVIMENTOS SOCIAIS E A ESQUERDA POLÍTICA NA AMÉRICA LATINA
}

\author{
$\operatorname{Carlos}$ A. Gadea*
}

\begin{abstract}
Este texto procura realizar uma breve análise sobre as inquietudes teóricas e analíticas no estudo dos movimentos sociais. Nesse sentido, são estabelecidas algumas pautas de análise para uma compreensão e uma interpretação mais adequada dos fenômenos coletivos contemporâneos. Por outro lado, o texto dedica-se a articular o marco analítico sobre movimentos sociais com o percurso político e social vivido pela esquerda política no Uruguai, principalmente a partir do processo de redemocratização política da década de 80 . Finalmente, é discutido o espaço político cultural ocupado hoje por essa corrente no governo nacional, sugerindo algumas interpretações sobre o significado histórico no nosso presente.

PALAVRAS-CHAvE: teorias dos movimentos sociais, teoria social, esquerda política, Uruguai, América Latina.
\end{abstract}

\section{INTRODUÇÃO}

É notória a existência de um nexo entre o trabalho teórico sobre os movimentos sociais e as preocupações da esquerda política na América Latina. Mais que isso: esse vínculo vai além dos próprios critérios analíticos, ao produzir, de fato, uma estreita relação entre as manifestações sociais do protesto e a própria atuação da esquerda política. Se partirmos desse simples diagnóstico, é possível afirmar que essa singular relação é fruto dos contextos históricos dos anos 1960 e 1970. É necessário levar em consideração que, de forma clara, na América Latina, movimento social e esquerda política construíram um binômio histórico e empírico que determinou os desenhos analíticos posteriores de uma suposta sociologia sobre os movimentos sociais. Para além de "lógicas situacionais" particulares, contextos e vicissitudes

* Doutor em Sociologia Política. Professor do Programa de Pós-graduação em Ciências Sociais da Universidade do Vale do Rio dos Sinos - UNISINOS. Pesquisador do CNPq-2.

Universidade do Vale do Rio dos Sinos - Centro de Ciências Humanas - 1. Av. Unisinos, 950 - Bairro Cristo Rei. Cep: 93.022-000 - São Leopoldo - Rio Grande do Sul Brasil.cgadea@unisinos.br socioculturais, na América Latina, dificilmente os movimentos sociais puderam se manifestar (e ser pensados) com autonomia frente à atuação da esquerda política que, em termos gerais, elaborou (e privilegiou) seu espaço de atuação no jogo político institucionalizado.

Apesar disso, durante os anos 1980 e 1990, demandas, identidades e estratégias de mobilização evidenciaram um esforço paulatino para demonstrar um processo de autonomização dos movimentos sociais com respeito ao cenário político institucional clássico, esforço que foi rapidamente traduzido ao âmbito analítico. ${ }^{1}$ Falava-se de "novos atores", de "novas demandas", de "novos sujeitos". De certo modo, tratava-se, realmente, de "novas ações coletivas" e de temas também novos na agenda política. Contudo, e talvez de forma coerente com os processos históricos do continente, há uma faceta desse "novo cenário" que não pode ser negligenciada, faceta ou aspecto tratado no presente texto: procurar evidenciar como a autonomia dos movimentos sociais frente à vida po-

${ }^{1}$ Vide, por exemplo, o excelente trabalho organizado por Scherer-Warren e Krischke (1987). 
lítica institucional é de difícil constatação ou, no melhor dos casos, uma demonstração de processos políticos e sociais que tendem a ser compreendidos a partir dos ciclos históricos de mobilizações sociais que têm, na figura do Estado, seu eixo de gravitação.

\section{PERSPECTIVAS ANALÍTICAS}

O autoritarismo político, a contracultura e os diferentes atores políticos organizados no final dos anos 1960 e durante os anos 1970 e 1980 oferecem material teórico e empírico necessário para a constituição de uma sociologia sobre os movimentos sociais na América Latina. ${ }^{2}$ Em linhas gerais, essa sociologia é apresentada a partir de três inquietudes e critérios analíticos fundamentais, acordes com a proliferação de novos conflitos sociais, cenários, atores, formas de organização e demandas.

Inicialmente, os movimentos sociais parecem definir-se como "contestação" ao sistema simbólico de justificações utilizado pela dinâmica político-institucional em vigor, para legitimar sua existência, originando, desse modo, formas politicamente organizadas de oposição. Faz-se referência a um contexto social que opõe, por exemplo, durante a década de 1970, a "democratização política” à dinâmica autoritária de certas formas de governo e lógica institucional (é o caso das denominadas "ditaduras militares"). Os movimentos sociais se apresentavam como eminentemente políticos, centrando suas inquietudes ao redor da figura do Estado e de atores político-sociais tradicionais: sindicatos, movimentos populares e de massa, setores sociais muitas vezes pertencentes a estruturas partidárias (Gohn, 1997). Alguns desses movimentos se expressavam também na forma de lutas armadas, baseadas em princípios ideológicos e políticos como o marxismo-leninismo, o "guevarismo" (em referência à gesta revolucionária do "Che" Guevara) ou o "foquismo" (estratégias de ação clandestinas que procuravam uma su-

${ }^{2}$ Um exemplo paradigmático é o extenso e clássico trabalho de Touraine (1989). posta instauração de Estados socialistas na região). O clima político e social era de total efervescência, com atores que pareciam emergir continuamente de conflitos previsíveis, de lutas sociais que norteavam os destinos daqueles que acreditavam ser portadores de um diagnóstico político privilegiado. Os movimentos sociais, às vezes sob a roupagem de um grupo armado, eram interpretados a partir de um quadro analítico que subordinava as particularidades da ação aos condicionantes estruturais e sistêmicos, à produção econômica e à lógica do trabalho assalariado.

Das experiências sociais de luta contra o autoritarismo de Estado surge uma preocupação mais relacionada com a "ampliação da cidadania", a modernização econômica e a reestruturação do Estado (Calderón, 1995; Calderón; Santos, 1995). Deixa-se para trás os anos 1960 e 1970 para que, no final dos anos 1980 e durante os anos 1990, a noção de "sociedade civil" passe a ser revisitada, ao mesmo tempo em que novas configurações estratégicas e identitárias, como as denominadas Organizações Não-Governamentais (ONGs), se transformam em objeto privilegiado de análise para muitos autores (Jelin, 1994; Cortez Ruiz, 1994; Lechner, 1990; Scherer-Warren, 1999). Frente à diversidade de conflitos e atores, a análise dos movimentos sociais adquire fôlego e sustento não tanto no terreno político institucional específico, mas sim no "espaço anti-sistêmico do mundo da vida" (Beyme, 1994, p. 210-264). A noção de esfera pública aparece como categoria analítica que permite ampliar a dimensão do "político", dando lastro teórico à atuação dos movimentos sociais. A teoria crítica e, em particular, os trabalhos de Jürgen Habermas, têm aí influência decisiva. Nesse aparente novo contexto, a democratização política e social torna-se tema central das inquietudes analíticas, sem nenhuma trégua aos possíveis sintomas de ações coletivas que denotassem o heterogêneo cenário social e cultural que se estava vivendo.

Uma terceira preocupação analítica se apresentou quando, na sociologia em geral, ingressa o debate sobre a globalização. Com esse novo pano de fundo, as análises sobre os movimentos sociais 
parecem redefinir-se em termos da localização e observação daqueles que seriam os atores mais visíveis ou emergentes (García, 1994). Ainda que as questões de gênero e étnicas já tivessem se explicitado previamente, nesse novo contexto os estudos sobre a identidade dos movimentos sociais assumem o centro das atenções (Dietz, 1995; Muñiz, 1997; Nagengast, 1997). Do mesmo modo, as análises sobre as estratégias de ação e mobilização a partir da noção de "rede" nutriram as dinâmicas de mobilização de premissas renovadas de compreensão no novo contexto da globalização (Riechmann; Buey, 1994; SchererWarren, 1996). As análises sobre as identidades e as estratégias se tornaram centrais, e os movimentos sociais já não podiam ser abordados a partir de enfoques que não considerassem que, no âmbito local e da globalidade, já não existiriam distinções analíticas precisas e evidentes.

\section{OS IMPASSES DO PANÓPTICO ACADÊMICO}

Qual é a situação atual dessa sociologia sobre os movimentos sociais na América Latina? De antemão, é possível perceber que certos clichês permanecem. Ao realizar uma rápida leitura sobre muitas das produções acadêmicas recentes sobre o tema, percebe-se uma insistência em modelos interpretativos que parecem reiterar a nomenclatura, problemáticas e estratégias de análise próprias de contextos ou ambientes sociais imediatamente posteriores às aventuras políticas autoritárias, modelos vinculados à transição democrática dos anos 1980. ${ }^{3}$ Não há dúvidas de que as sociedades latino-americanas ainda possuem carências significativas de democratização política e social, mas entender apenas que os movimentos sociais lutam para “democratizar a sociedade", por se contrapor ao poder do Estado, ou por denunciar um modelo econômico injusto, restringe o sentido e o significado sócio-histórico que esses movimentos pos-

${ }^{3}$ Existe uma grande quantidade de trabalhos que demons-
tram essa tendência, mas prefere-se não citá-los para tram essa tendência, mas prefere-se não citá-los pa
não gerar possíveis situações de desconformidade. suem, na atualidade. Nada muito diferente se diz perante explicações que reafirmam uma constatação que é própria da dinâmica e origem dos movimentos sociais dessas regiões, explicações que possuem capacidade para se reproduzir sem grandes inconvenientes. Um problema fundamental associado a essa tendência consiste talvez no fato de que (e com referência a muitos centros acadêmicos considerados de excelência), entre alguns jovens acadêmicos e intelectuais, tornou-se mais prestigioso continuar sem questionar as rígidas diretrizes de seus professores e orientadores de tese, do que procurar explicações analíticas próprias. Essa atitude pode lhes garantir espaço intelectual bastante mais seguro, livre das asperezas e inseguranças do mundo acadêmico de hoje, embora possa também gerar inércia e certo espírito paralisante de um saudável dinamismo acadêmico exigido pelos tempos atuais.

Duas eventuais "fatalidades" influenciam a sociologia sobre os movimentos sociais na América Latina. A primeira, menos visível, ainda que de enorme repercussão acadêmica, diz respeito à manutenção dos seus "espaços de poder discursivo" por parte de toda uma geração de intelectuais. Uma série de premissas epistemológicas subjaz entre aqueles que não parecem permitir que novas discursividades entrem em cena, minando o cenário acadêmico de vícios de linguagem e "ideologias" que pouco contribuem para a ampliação do espaço democrático de construção do saber. Ou seja, mesmo que muitas das temáticas apresentadas na atualidade possuam ampla legitimidade, ao tentar aportar conhecimentos e perspectivas originais ao debate sobre os movimentos sociais, em geral podem ser inscritas dentro de uma linha clássica e previsível de análise e discurso. A formação acadêmica parece, assim, demandar uma espécie de "exercício circular" que nos conecta com a rica produção analítica daqueles que pesquisaram durante muito tempo o tema. Não é preciso assinalar a extensa lista de intelectuais e pensadores latinoamericanos que abordaram os movimentos sociais como objeto de estudo; alguns, de uma forma ou outra, parecem nascer na sociologia a partir desse subcampo analítico. O mais interessante a desta- 
car é que muitos deles continuam marcando as pautas de pesquisa relacionadas às mobilizações políticas e sociais da atualidade, talvez cuidadosos de suas inconfundíveis contribuições teóricas e descobertas empíricas, que são imediatamente tomadas como paradigmáticas para a observação de outros casos concretos. Ocupando lugares de privilégio dentro da academia e nos institutos de pesquisa, adotam, queiram ou não, uma posição política sustentada na não-necessidade de legitimar seu próprio lugar de enunciação discursiva. Na atualidade, é possível perceber (assim como em tantas outras áreas de pesquisa nas ciências humanas) que esse intelectual parece falar a partir de um saber presumivelmente válido e autolegitimado, que o autoriza a falar pelos "outros", delinear horizontes de pesquisa e outorgar confianças particulares em função de lealdades acadêmicas. Dessa forma, essa espécie de "movimentólogo" fala, sabendo ou não, a partir de um espaço de inconfundível "controle do conhecimento", a partir da "torre do vigia", no panóptico acadêmico. Herdeiros inevitáveis de uma forte tradição sobre o tema, outros pesquisadores que ousam aventurar-se a pensar os movimentos sociais sob outra perspectiva não têm alternativa a não ser a de transitar numa "linha de tensão", que representa dar continuidade a tal tradição e, por outro lado, ensaiar e arriscar conteúdos hermenêuticos presumidamente mais contemporâneos para explicar fenômenos cada vez mais complexos.

Não menos importante, uma segunda "fatalidade" toma forma nos últimos tempos, a partir de um curioso deslocamento sofrido pelos estudos sobre os movimentos sociais. Trata-se de um deslocamento traduzido numa espécie de "colonização acadêmica" por parte de enfoques, temas e experiências empíricas que negligenciaram as "antigas" e as "novas" problemáticas tratadas no âmbito da sociologia dos movimentos sociais até os anos $1990 .{ }^{4}$ De fato, ao final daquela década, as

" Para observar as "antigas" e "novas" questões tratadas por uma sociologia dos movimentos sociais sugere-se o interessante trabalho de Klandermans (1992). Para uma compreensão mais específica e crítica dessas discussões geradas nos anos 1990 vide o interessante trabalho de Gurza Lavalle (2003) teorias e temas relacionados à discussão sobre as ações coletivas e os movimentos sociais foram praticamente abandonados, assumindo seu lugar perspectivas e preocupações mais relacionadas com uma "institucionalização" de suas práticas. Dentro dessa pauta, apareceram reflexões em torno das políticas públicas que contemplariam "novos" atores das mobilizações sociais, agora incorporados à lógica política institucionalizada, assim como temáticas seduzidas pelas novas formas de "gestão social” e as formas de participação política no âmbito de diferentes instâncias estatais ou paraestatais. Aparentemente, um perfil mais inserido na ciência política se sobrepunha a outro mais sociológico sobre o tema. Dessa maneira, os atores sociais apareciam desvinculados de uma dimensão associativa que os enquadrava em cenários de conflito político e social; criadores de instâncias coletivas de ação em constante ressiginificação e em eventual situação de antagonismo frente ao cenário político institucional. ${ }^{5}$ De forma similar, não foram consideradas com clara evidência e seriedade, as novas dinâmicas associativas de organizações cada vez mais heterogêneas no cenário global, as novas estratégias de ação coletiva e as novas redes sociais, de certo modo impulsionadas pelas transformações próprias da "era da informação" (Castells, 1996).

O abandono do debate sobre o caráter inovador dos "novos" movimentos sociais tornou-se patente, e, em seu lugar, emergiu uma nomenclatura acorde com as discussões clássicas da ciência política: a representação e a participação política. Para muitos que se presumiam integrados a uma sociologia dos movimentos sociais, com seus respectivos limites disciplinares, termos como "orçamento participativo", "gestão social”, "conselhos deliberativos" e todos aqueles que pareciam subordinar a ação coletiva a uma mera questão de administração política e institucional soaram como um verdadeiro sacrilégio. Contudo, apesar disso, pode-se perceber que muitos debates teóricos sur-

${ }^{5}$ Deixando de lado a tradição pós-estruturalista e esquecendo-se, por exemplo, de trabalhos clássicos como de Laclau e Mouffe (1987). 
giram com a finalidade de não reorientar unicamente o debate sobre as ações coletivas e manifestações de protesto nas trilhas dessa sociologia, mas sim de atualizar temas e perspectivas teóricas que se apresentam como fundamentais para a compreensão dos movimentos sociais contemporâneos. Eles surgem com a tentativa de avaliar as novas formas de ação que se referem a estratégias e identidades coletivas que alteram a própria concepção da política, do ator social e do próprio horizonte da democracia.

Talvez esse deslocamento corresponda à chegada de forças políticas de esquerda a vários governos na região. O interesse por parte de certa intelectualidade e setores acadêmicos em "acompanhar" as vicissitudes políticas dessa esquerda conduziu, aparentemente, a que as ações coletivas que não se enquadrassem dentro desse novo cenário estivessem fora do eixo central de discussões e análise. Em outras palavras, "uma" sociologia sobre os movimentos sociais parece ter se inclinado para a análise de iniciativas do poder público (que se desprendem, em ocasiões, da própria sociedade civil) como correlato à geração de participação política efetiva em antigos ou novos espaços de exercício de democracia.

\section{MOVIMENTOS SOCIAIS, INSTITUCIONALIDADE E ESQUERDA POLÍTI- CANOURUGUAI}

Seguindo a lógica apresentada, proponho uma inflexão nessa discussão, para considerar uma experiência política e histórica concreta que apresenta preocupações análogas às dessa sociologia sobre os movimentos sociais. Por exemplo, ao observar a trajetória política e social de um país como o Uruguai, é habitual buscarem-se explicações para sua suposta institucionalização política eficiente a partir de uma cultura democrática amplamente interiorizada. Assim, foi distribuído o capital cultural e social durante a sua história política, atribuindo-se essa dinâmica a modelos modernizadores e racionalizadores "exitosos". Um Estado que "pro- tege" os seus cidadãos e uma consequente "sacralização das instituições" e dos valores sociais sustentados nelas acabam convertendo-se nos dois traços mais notáveis dessa cultura presumidamente moderna. Orgulhosos de tal reconhecimento, os uruguaios tendem a dar soluções a seus desajustes políticos e culturais conjunturais a partir da eventual "operacionalidade" de suas instituições, aportando, dessa forma, outros traços também característicos: um conservadorismo acentuado e um excessivo ideário de segurança, certeza e confiança nas instituições (Rama, 1987).

Na atualidade, essa dinâmica institucional e a confiança que a acompanha parecem persistir, ainda que com certos receios. A etapa histórica e política iniciada com a denominada "abertura democrática” do ano 1985 pode ser vista como portadora de uma série de sinais que questionam alguns dos postulados histórico-institucionais clássicos. Uma crise econômica inédita (como a vivida durante os anos 2002 e 2003) e uma paulatina e progressiva deterioração das condições de vida material e cultural levam o Uruguai a uma disjuntiva institucional complexa, que vem acompanhada de uma inevitável revisão de sua exagerada autoestima legitimada na crença de ser uma sociedade democrática, tolerante frente à diferença e presumidamente igualitária.

Já com a "abertura democrática”, em meados dos anos 1980, a tradição política e a estabilidade institucional não puderam ocultar certos problemas que, com o decorrer do tempo, acabaram se traduzindo em um estado de ânimo de desencanto cada vez mais visível. Por exemplo, importa lembrar como, no ambiente democrático daqueles anos (1985-1989), vários movimentos sociais e culturais (de direitos humanos, juvenis, de associações de bairro, comunitários, ambientalistas, "alternativos") ganharam expressividade, mantendo certa autonomia frente ao sistema político, ainda que a falta de imaginação e uma percepção da prática política restrita aos canais institucionais mais clássicos de expressão tenham resultado no seu desaparecimento, ou, em alguns casos, na sua absorção por parte de setores e de partidos políti- 
cos de esquerda (Perelli; Rial, 1986). Essa tendência acabou por determinar um dos problemas e "desencantos" iniciais com o processo de democratização política: aquele que se refere à incapacidade e aos interesses práticos de um sistema político que não encontrou outra via senão buscar uma reacomodação da nova situação social, surgida no ambiente cultural e político de redemocratização, dentro da normatividade e institucionalidade política pré-existente, no lugar de tentar gerar uma nova normatividade para a nova situação real de poder social (Krischke; Gadea, 2000).

Façamos um exercício de memória: um dos sinais mais agudos disso foi a própria campanha de repressão policial durante o governo do presidente Julio María Sanguinetti (1985-1989), que, através de "blitz" (razzias), detenções indiscriminadas e um suposto discurso de combate ao consumo de drogas, conseguiu gerar um forte descontentamento entre a população mais jovem (Bayce, 1989). Se o clima político era de "abertura", no âmbito cultural ela não era tão visível, apesar do grande agito juvenil em torno do rock nacional. Se o movimento político era um fato, ele apresentou uma reconfiguração que acabou por reafirmar as estruturas políticas tradicionais, as estruturas partidárias e os alinhamentos políticos do período anterior à ditadura. Tudo aquilo que transgredisse tal lógica era simplesmente ignorado ou excluído e, no melhor dos casos, reformulado dentro de uma força política em crescimento, até aquele momento, também crítica dessa lógica política e institucional: a Frente Ampla, a "esquerda política”. Sustentado no mito de uma história política estável, o sistema político uruguaio parte de um princípio de regulação e ordem normativa que somente atribui direitos representativos e de expressão àqueles representantes eleitos através de eleições políticas nacionais. Desse modo, todos os interesses sociais surgidos são definidos como grupos de pressão "clientelizáveis" e deslegitimados, a não ser que se submetam à "mediação" do partido político ou do Estado (Rico, 2005).

Pode-se compreender que a denominada “abertura democrática” no Uruguai dá seus últi- mos passos no ano de 1989, com o plebiscito para derrogar a "Ley de Caducidad de la pretensión punitiva del Estado" (lei que permite anistiar militares e policiais vinculados aos atos de violação aos direitos humanos durante o período do governo cívico-militar, compreendido entre 1973 e 1985). Esse acontecimento sentenciou e reafirmou a bipolaridade política histórica do país. Como é sabido, o "voto amarelo" (a favor da lei) triunfou sobre o "voto verde", e o debate concernente às características gerais da "democracia re-emergente" chega ao fim. A efervescência social gerada pela mobilização em prol do "voto verde" foi dando lugar, paulatinamente, a uma apatia com sabor de desencanto. Forças sindicais cansadas e debilitadas, apesar do crescimento do nível de conflitividade social, uma esquerda política também anestesiada e muitos jovens militantes entram em um clima de frustrações e de novos desejos pessoais. Já nos anos 1990, uma crescente indiferença política e a crise da militância tradicional de esquerda são sintomas claros do novo ambiente político. Finalmente, um alívio para os desmotivados ex-militantes veio com o triunfo eleitoral da Frente Ampla em Montevidéu. Crise econômica, governos frágeis e incapazes. Assim continua a história político-institucional até a atualidade.

É certo que a esquerda política uruguaia, simbolizada na Frente Ampla, transformou-se, no final dos anos 1990, na força política majoritária no país. Novos setores políticos e sociais aglutinaram suas forças na conformação de uma proposta eleitoral eclética que, na atualidade, resume-se no chamado Encuentro Progresista - Frente Amplia - Nueva Mayoría. É fácil notar que essa é uma esquerda política distinta daquela que se observava anos atrás, abandonando velhos clichês e comportamentos políticos de enfrentamento direto frente às "agências do capitalismo mundial", como o FMI e o BID. Mais pragmática e mais experiente, propõe políticas de inserção econômica do pequeno país, da melhor maneira possível, no contexto regional e global. Sendo a força política atualmente majoritária e demonstrando estar mais amadurecida para enfrentar as situações críticas 
do país, parece converter-se praticamente na "única" alternativa para a maioria dos uruguaios, angustiados e cansados de tudo o que está relacionado ao estritamente político. ${ }^{6}$

O que se pretende ressaltar é que a própria indiferença política e o desejo coadjuvante por reduzir a rigidez da burocracia e a institucionalidade historicamente consolidada são fatores que, entre outros, permitem esse crescimento rápido da esquerda política uruguaia, a identificação da população como uma "alternativa menos pior" (como dizem muitos cidadãos nas ruas) frente aos outros setores. Nada de "consciência política”, militância em crescimento e, muito menos, de jovens politizados. Aqueles que, dentro da própria esquerda, acreditam nisso, ainda veem com velhos olhos esses novos contextos. Pode haver uma percepção da população frente ao caráter mais legítimo (com relação a suas propostas e conduta) dos dirigentes dessa força política, mas isso não quer dizer que tenha sido a capacidade de convocatória política e social o que determinou o crescimento potencial do eleitorado uruguaio de esquerda. Em outros contextos históricos, a esquerda política chegou a convocar e a mobilizar mais adeptos que nos atuais momentos de crise social. Por isso, ela deve, também, ser entendida como parte desse clima social de "desencanto" que hoje representa o desafio mais auspicioso para a atual lógica político-institucional do país.

Frente a esta situação, permitam-me lançar duas considerações sobre a esquerda política uruguaia, que só poderão ser confirmadas com o passar do tempo histórico. Em primeiro lugar, que a atual esquerda política do Uruguai (cada dia menos homogênea, apesar de seu desejo de unidade) é um claro "espaço de transição”, no sentido de agendar uma cultura política diferente, na qual os mecanismos de expressão política e cultural deixam de ser instrumentados e canalizados a partir dos aparelhos institucionais e das práticas políti-

\footnotetext{
${ }^{6}$ Uma das muitas reflexões recentes sobre o tema afirma: “... que o governo da FA - Frente Ampla - perdeu o apoio dos votantes de centro que em 2004 votaram na FA, por cansaço e desencanto frente aos partidos tradicionais" (De Riz, 2008).
}

cas tradicionais. O “novo contexto” político-social encontrará novos desafios, entre os quais um dos principais é a capacidade de lidar com novas construções discursivas e "mundos de vida", por vezes profundamente autônomos dos desígnios institucionais e políticos legitimados. Haverá de se comprovar em que medida essa esquerda política - hoje no governo nacional -, que soube circular nas margens do sistema político nos anos 1970 e em grande parte dos 1980, é capaz de abalar a tendência estrutural de influenciar todas as formas de expressão social e cultural, sendo capaz de simplesmente ser mais uma partícipe de uma nova cultura política menos subordinada à rigidez da institucionalidade tradicional e histórica do país. A segunda consideração pode estar situada na contracorrente do que seria supostamente observável (e desejável) dessa esquerda política (e da cultura política em geral), ao não pretender negligenciar um aspecto estrutural do processo político e histórico desse pequeno país. Para a surpresa de muitos (ou não tanto), e nas condições históricas atuais, é possível supor que essa esquerda política, seguindo os ensinamentos de Braudel (1978) sobre os processos históricos de longue durée, encarna a "continuidade políticoinstitucional” de uma forma política de proceder e de definir as tarefas do Estado, assim como havia sido feito pelo Partido Colorado no seu momento de maior influência no país (1905-1929). ${ }^{7}$ O Partido Colorado, sob as presidências de José Battle e Ordoñez, no começo do século XX, foi portador de uma atuação política que não somente ampliou direitos sociais para a cidadania, como também deu corpo a uma estrutura estatal que podia ser considerada de vanguarda para a época, iniciando políticas de forte caráter social-democrata. ${ }^{8}$ Em grandes linhas, o Partido Colorado encarnava os inte-

${ }^{7}$ Vide Nahum (1998).

${ }^{8}$ A gestão financeira (criação de Bancos), industrial (criação de empresas de energia elétrica e telefones em 1912) e comercial do Estado se constituiu em um elemento definitivo da relação entre a sociedade e o Estado no começo do século XX. No âmbito social, a "lei do divórcio" é do ano 1913, a de "oito horas" de trabalho do ano 1915 e a que outorga o direito ao sufrágio feminino é do ano 1932. Esse perfil político-ideológico ficou conhecido historicamente como "batllismo". 
resses da ampla cidadania uruguaia, modelando uma estrutura social em cuja base se situava uma ampla classe média de funcionários, empregados de comércio, operários de fábricas e profissionais. Mas, como era de se supor, essa "aura social-democrata” não duraria muito tempo. Pode-se dizer que foi abandonada nos anos 1960, ${ }^{9}$ ocupando espaços que oscilavam entre sindicatos de trabalhadores, movimentos políticos de uma esquerda política tímida em termos quantitativos e, de certo modo, entre alguns movimentos sociais que apelaram à luta armada para "tomar o poder" no final dos anos 1960 e início dos anos 1970.

De acordo com esse raciocínio, quando se escuta que a esquerda política atual deve tomar medidas que busquem reduzir as desigualdades salariais, dar acesso a determinados direitos sociais e à necessidade de uma ampla reforma do aparelho estatal (para torná-lo mais eficiente, sem perder poder de incidência nos destinos econômicos do país), parece que se está assistindo a um “continuum" histórico-temporal que transfigura o outrora Partido Colorado na atual Frente Ampla. Certamente, não são discursos ou iniciativas políticas concretas que permitem dizer que, em certo sentido, a Frente Ampla é a continuidade do Partido Colorado em situações históricas diferentes. É também o lugar que ela passou a assumir no repertório político do país, tomando como próprio um espaço discursivo (antes ocupado pelo tradicional Partido Colorado), que situa a figura do Estado no centro das atenções, interesses e perspectivas de futuro. É dessa forma que o sistema político e a institucionalidade do livre jogo democrático no país consegue retornar às suas fontes originais: a uma estrutura político-partidária que dá continuidade a um "ser nacional” que não encontrou melhor abrigo senão na força política de esquerda atual, a eclética Frente Ampla. A bipolaridade política continua vigente: deslocado a um terceiro lugar dentro das preferências do elei-

${ }^{9} \mathrm{O}$ outro momento histórico no qual se encarnou uma aventura política similar foi durante o denominado "neobatllismo", sob a influência política de Luis Batlle Berres (sobrinho de José Batlle y Ordoñez) entre os anos 1947 e 1958. torado, o Partido Colorado vagueia na busca de uma nova identidade, inevitavelmente perdida por aqueles que souberam captar o capital político e social histórico do país.

\section{POR UMA SOCIOLOGIA DOS MOVIMENTOS SOCIAIS}

Retomemos as discussões que deram origem a este texto. Constata-se claramente que atores e cenários atuais não parecem ser tão diferentes daqueles observados nas etapas analíticas brevemente mencionadas. Parecem justapor-se as problemáticas e sedimentar-se aqueles atores e demandas que têm dado conteúdo e sentido aos movimentos sociais. As reivindicações por emprego e melhores condições de vida material permanecem, assim como aquelas demandas por respeito à diferença cultural e uma determinada identidade social também não desapareceram frente à voragem da complexidade contemporânea. Ao contrário, revalorizaram-se. O que cada dia mais parece perceptível é a possibilidade de os movimentos sociais se manifestarem através de formas "pré-políticas" de resistência, ou através de formas reativas de comportamento, de lógicas pragmáticas de ação. ${ }^{10}$ Apesar do destaque dado à relação entre sociedade civil e Estado por boa parte das análises sobre os movimentos sociais nos anos 1990, é preciso ter em conta que isso é próprio de um esforço por compreender a aposta realizada e o eventual êxito de muitos atores da denominada sociedade civil para criarem e ocuparem espaços institucionais. Sem dúvidas, tal processo trouxe dimensões políticas e de participação interessantes, na medida em que, eventualmente, esses atores participaram, minimamente, de certos "consensos institucionais” e premissas de ação a priori inseridas no jogo político legitimado. Sobre isso, não podemos nos equivocar. Para muitos outros movimentos sociais, construídos simbolicamente

${ }^{10}$ A filosofia de Rorty $(1991,1997,1998)$ é bastante
eloquente para ampliar a compreensão desse fenômeno. 
de maneira diferente (por exemplo, o neozapatista do México), as alternativas e possibilidades são radicalmente distintas. Quando a crítica e a definição da ação concreta transgridem os limites do jogo político legitimado, os movimentos sociais não só não encontram canais políticos e sociais de expressão, como também parecem desafiar sua própria legitimidade e fundamentação simbólica (Gadea, 2004).

As formas "pré-políticas" de ação referemse à possibilidade de definir os movimentos não exclusivamente como simples atores da arena política, mas como "modelos de sociabilidade" que ainda demonstram a multiplicidade de elementos discursivos que podem atuar em estratégias e ocasiões diferentes, sem consentir a dinâmica e os marcos de ação "toleráveis" no jogo político prédeterminado. Pense-se, por exemplo, que nem sempre a "alta institucionalização" política na América Latina, como no caso do Uruguai, representou avanços nos modelos sociopolíticos integradores e democratizantes, mas sim uma afirmação de um "consenso" que, de forma perversa, limitou atores potenciais emergentes que pretenderiam transformar códigos normativos específicos.

Do ponto de vista analítico, se a tendência é de repensar os movimentos sociais, considerando a diversidade de ambientes históricos da América latina, é preciso não só deixar que os atores implicados "falem", ou delinear pautas organizacionais, reduto potencial onde se pretende descobrir práticas sociais democráticas. Torna-se fundamental realizar uma "fenomenologia dos movimentos sociais", ou seja, "compreendê-los" relativizando pressuposições teóricas e analíticas. Trata-se de um recurso de desconstrução que permite desfazer os pressupostos cristalizados. Essa "fenomenologia"11 convida a prestar atenção às atitudes e intenções axiológicas práticas e estéticas dos movimentos sociais atuais, para, dessa forma, compreender de que maneira eles se constituíram, que processos de subjetivação experimentaram, a partir de que

${ }^{11}$ Segundo a brilhante tradição representada por autores
como Schütz (1962, 1964), Schütz e Luckmann (1973), como Schütz (1962, 1964), Schütz e Luckmann (1973)
Berger e Luckmann (1997) e Lyotard [1954] (1989). construção social da realidade se apresentam e que projetos integram suas realidades práticas.

Nessa linha, existe uma tradição sociológica que constitui uma base indispensável, aquela que se refere ao "impressionismo sociológico" de Simmel (1977), à psicologia social de Mead (1982), à "fenomenologia" de Schutz (1962, 1964), ao “interacionismo simbólico" de Blumer (1969) e à “etnometodologia” de Garfinkel (1984). A ênfase nos modelos de análises que reservam vínculos com as perspectivas de estudos sobre o collective behavior pode ser percebida plenamente, já que os contextos sociais, culturais e políticos vividos atualmente sugerem observar as ações coletivas como "ocasiões" em que novas definições compartilhadas de uma situação (Thomas, 2005) geram uma coletividade e laços de solidariedade que, consequentemente, são mobilizados para a ação. Os alinhamentos analíticos que supõem o emprego de perspectivas do denominado "interacionismo simbólico" oferecem um conjunto de elementos básicos para uma teoria não determinista dos movimentos sociais, algo que, não é de mais dizer, supõe afastar-se de toda uma tradição sociológica que vai desde o marxismo clássico à teoria do sistema-mundo, em que a "liberdade dos atores" parecia submetida ao determinismo da alienação econômica. Para essas perspectivas, os movimentos sociais apareceriam como simples reflexo de condicionantes que o sistema de dominação econômica produz na política e na cultura. É preciso ir além desses enfoques. Nesse sentido, a tradição sociológica do "interacionismo" contrapõe-se diretamente a toda a intenção de observar a ação coletiva determinada por estruturas sociais "mais gerais" ou "abstratas", apoiando-se, fundamentalmente, na tradição pragmática e empirista (James, 1961). Obviamente, isso não significa uma ingenuidade analítica, nem um jogo político-acadêmico que pretende negligenciar os aportes metodológicos e as concepções societárias subjacentes a uma sociologia herdada do estruturalismo. Nada disso. O que se pretende é apelar para ferramentas analíticas que permitam aportar uma dimensão crítica à própria forma de análise 
dos movimentos sociais, tendo em conta o fluxo constante de comunicação e inter-relação da sociedade global atual.

Finalmente, é preciso considerar que os movimentos sociais são "comunidades de valores" com alta densidade de interação entre seus integrantes. São reflexo de redes socioespaciais capazes de se precipitarem em situações definíveis como favoráveis (Melucci, 1998). Dessa maneira, são "modelos de sociabilidade” (Gadea, 2007). Observar a forma dessa sociabilidade, a maneira como acontece, como se transforma, que sistema simbólico questiona, que projetos estão implícitos no seu aparecimento, que supostas regras de convivência alternativas oferecem, que discurso lhes pertence e a partir de que construção da realidade social se manifestam pode ser uma simples contribuição à análise (em certa medida uma espécie de "reedição”), para compreender o sentido e o significado das ações coletivas e dos movimentos sociais atuais.

(Recebido para publicação em outubro de 2008) (Aceito em dezembro de 2008)

\section{REFERÊNCIAS}

BAYCE, Rafael. Cultura política uruguaya: desde Batlle hasta 1988. Montevideo: Ed. Fondo de Cultura Universitaria, 1989.

BEYME, Klaus von. Teoría política del siglo XX. De la modernidad a la postmodernidad. Madrid: Alianza Editorial, 1994.

BERGER, Peter; Luckmann, Thomas. A construç̃o soci al da realidade. Petrópolis: Ed. Vozes, [1966] 2001.

BLUMER, Herbert. Simbolic interacionism. Nova Jersey: Ed. Prentice-Hall, 1969.

BRAUDEL, Fernand. Escritos sobre a história. São Paulo: Ed. Perspectiva, 1978.

CALDERON, Fernando. Movimientos sociales y política: la década de los ochenta en Latinoamérica. México D.F. Siglo XXI, 1995

; Santos, Mario dos. Sociedades sin atajos. Cultura, política y reestructuración económica en América Latina. México D.F.: Siglo XXI, 1995

CASTELLS, Manuel. La era de la información. Economía, sociedad y cultura. Madrid: Alianza Editorial, 1998a. v.1 La sociedad red.

. La era de la información. Economía, sociedad y cultura. Madrid: Ed. Alianza, 1998b. v. 2 El poder de la identidad.
CORTÉZ RUIZ, Carlos. Las organizaciones no gubernamentales: un nuevo actor social. Revista Mexicana de Sociología, México, UNAM, n. 2, p. 149-157, 1994.

DE RIZ, Liliana. Uruguay. La política del compromiso. In: CASTILLO, Rolando; COSATA, Jimenez; FLORES, Elena. Cultura política y alternancia en América Latina. Madrid: Ed. Pablo Iglesias, 2008.

DIETZ, Gunther. Zapatismo y movimientos étnicoregionales en México. Nueva Sociedad, Caracas, n. 140, p. 33-50, 1995.

EVERS, Tilman. Identidade: a face oculta dos novos movimentos sociais. Novos Estudos CEBRAP, São Paulo, v. 2, n. 4, p. 11-23. 1984

FOUCAULT, Michel. El sujeto y el poder. Revista Mexicana de Sociología, México, UNAM, v. 50, n. 3, jul./sept., 1988.

GADEA, Carlos A. Acciones colectivas y modernidad global. El movimiento neozapatista. Toluca, México: Ed. UAEM, 2004

Paisagens da pós-modernidade: cultura, política e sociabilidade na América Latina. Iitajaí, SC: Ed. Univali, 2007.

GARFINKEL, Harold. Studies in ethnomethodology. Cambridge: Polity Press, 1984.

GARCIA, Illía. Movimientos sociales regionales y construcción de identidades regionales. In: MATO, Danie (Coord.). Teoría y política de la construcción de identidades y diferencias en América Latina y el Caribe. Caracas: Ed. Nueva Sociedad, 1994.

GOHN, Maria da Glória. Teoria dos movimentos sociais: paradigmas clássicos e contemporâneos. São Paulo: Ed. Loyola, 1997.

GURZA LAVALLE, Adrian. Sem pena nem gloria: o debate da sociedade civil nos anos 1990. Novos Estudos CEBRAP, São Paulo, v. 66, n. 66, p. 91-110, 2003.

JAMES, William. Pragmatismo. Buenos Aires: Ed. Aguilar, [1907], 1961.

JELIN, Elizabeth. ¿Ciudadanía emergente o exclusión? Movimientos sociales y ONGs en los años noventa. $R e$ vista Mexicana de Sociología, México, UNAM, n. 4, p. 91108, 1994.

KLANDERMANS, Bert P. La unión de lo 'viejo'con lo 'nuevo': el entramado de los movimientos sociales en los Países Bajos. In DALTON, J.; RUSSEL, Manfred; KEUCHLER (Comp.) Los nuevos movimientos sociales. Valencia, ES: Generalitat Valencia/Ed. Alfons El Magnànim, 1992.

KRISCHKE, Paulo; GADEA, Carlos A. Novos movimentos sociais no Brasil contemporâneo: debate teórico e comparacões históricas. Cadernos de Pesquisa Interdisciplinar em Ciências Humanas, Florianópolis, UFSC, n. 10, nov., 2000.

LACLAU, Ernesto; MOUFFE, Chantal. Hegemonía y estrategia socialista. Hacia una radicalización de la democracia. Madrid: Siglo XXI, 1987.

LECHNER, Norbert. Los patios interiores de la democracia. Subjetividad y política. Santiago de Chile: Ed. Fondo Cultura Económica, 1990.

LYOTARD, Jean-François. La fenomenología Barcelona: Paidós, [1954] 1989b.

MEAD, Georg H. Espíritu, persona y sociedad. Buenos Aires: Paidós, [1934] 1982.

MELUCCI, Alberto. Acción colectiva y transformación personal en la era de la información. Ciudades, México, $\mathrm{n}$. 37, p. 3-11, 1998. 
MUÑIZ, Elsa. Indigenismo, demandas étnicas y género: un camino a la democracia. Alegatos: revista, México, D.F n. 36, p. 261-268, 1997.

NAGENGAST, Carole. Women, minorities, and Indigenous Peoples: Universalism and Cultural Relativity. Journal of Anthropological Research, Albuquerque,Mx, University New Mexico, v. 53, n. 3, p. 349-369, 1997.

NAHUM, Benjamín. Historia uruguaya. La época Batllista: 1905-1929. Montevideo: Ed. Banda Oriental, [1975] 1998.

PERELLI, Carina; RIAL, Juan. De mitos y memorias políticas: la represión, el miedo y después..., Montevideo: Ed. Banda Oriental, 1986.

RAMA, Germán. La democracia en Uruguay. Una perspectiva de interpretación. Buenos Aires: Ed. Grupo Editor Latinoamericano, 1987.

RICO, Álvaro. ¿Cómo nos gobierna la clase gobernante? Orden político y obediencia social en la democracia postdictadura. Uruguay 1985-2005. Montevideo: Trilce, 2005.

RIECHMANN, Jorge; FERNÁNDEZ BUEY, Francisco. Redes que dan libertad. Barcelona: Paidós, 1994.

RORTY, Richard. Contingencia, ironía y solidaridad. Madrid: Paidós, 1991.

. ¿Esperanza o conocimiento? Una introducción al pragmatismo. Buenos Aires: FCE, 1997.

Pragmatismo y política. Barcelona: Paidós, 1998.
SCHERER-WARREN, Ilse. Redes de movimentos sociales. São Paulo: Ed. Loyola, 1996.

Cidadania sem fronteiras. Ações coletivas na era da globalização. São Paulo: Ed. Hucitec, 1999.

; Krischke, Paulo. Uma revolução no cotidiano? São Paulo: Ed. Brasiliense, 1987.

SCHUTZ, Alfred. El problema de la realidad social. Buenos Aires: Ed. Amorrortu, [1962] s/d.

Estudios sobre teoría social. Buenos Aires: Ed. Amorrortu, [1964] 1974.

; LUCHMANN, Thomas. Las estructuras del mundo de la vida. Buenos Aires: Ed. Amorrortu, 1973.

SIMMEL, Georg. Sociología. Madrid: Ed. Revista de Occidente, 1977.

THOMAS, William I. La definición de la situación. Cuadernos de Información y Comunicación, Santiago do Chile, Pontificia Universidad Católica do Chile, n. 10, [1923] 2005.

TOURAINE, Alain. Palavra e sangue. Política e sociedade na América Latina. Campinas: Ed. Universidade de Campinas, 1989.

¿Podremos vivir juntos? Iguales y diferentes. $\overline{\text { Buenos }}$ Aires: FCE, 1997.

Un nuevo paradigma para comprender el mundo de hoy. Buenos Aires: Ed. Paidós, 2006. 


\section{THE STUDY OF SOCIAL MOVEMENTS AND THE POLITICAL LEFT IN LATIN AMERICA}

\section{Carlos A. Gadea}

This paper tries to accomplish a brief analysis on the theoretical and analytical complicated issues in the study of the social movements. In that sense, some analysis lines are established for a more appropriate interpretation and understanding of the contemporary collective phenomena. On the other hand, this paper aims to articulate the analytical cornerstone on social movements with the political and social trajectory lived by the political left in Uruguay, mainly starting from the process of political redemocratization of the decade of 80. Finally, the cultural-political space is discussed as it is occupied today by that trend in the national government, suggesting some interpretations on its historical meaning in our present.

KEY wORDS: Social movements theories, social theory, political left, Uruguay, Latin America.

\section{L'ETUDE DES MOUVEMENTS SOCIAUX ET LA GAUCHE POLITIQUE EN AMERIQUE LATINE}

\author{
Carlos A. Gadea
}

Ce texte présente une analyse succincte des inquiétudes théoriques et analytiques dans l'étude des mouvements sociaux. A ce propos, des critères d'analyse sont définis pour permettre une compréhension et une interprétation plus adéquate des phénomènes collectifs contemporains. D'autre part, on cherche à rapprocher le référent analytique concernant les mouvements sociaux du parcours politique et social vécu par la gauche politique en Uruguay, surtout à partir du processus de re-démocratisation politique dans les années 80 . Finalement, c'est l'espace politique culturel actuellement occupé par ce courant au sein du gouvernement national qui est discuté, et l'on y suggère quelques interprétations de son sens historique dans le présent.

Mots-CLÉs: théories des mouvements sociaux, théorie sociale, gauche politique, Uruguay, Amérique Latine.

Carlos A. Gadea - Doutor em Sociologia Política pela Universidade Federal de Santa Catarina (UFSC). Realizou estudos e pesquisas no Ibero-Amerikanischen Institutes Berlin-IAI (Alemanha) em 2003 e na Facultad de Ciencias Políticas y Sociales da Universidad Nacional Autónoma de México - UNAM (México) em 2002. Professor do Programa de Pós-graduação em Ciências Sociais da Universidade do Vale do Rio dos Sinos - UNISINOS. Pesquisador do CNPq-2. Editor da Revista Ciência Sociais UNISINOS. Sua dissertação de Mestrado em Sociologia Política pela UFSC recebeu o Prêmio a Melhor Dissertação em Sociologia pela Sociedade Brasileira de Economia e Sociologia Rural (SOBER), no ano 2000, sendo publicada no México com o título Acciones colectivas y modernidad global. El movimiento neozapatista. Também é autor do livro Paisagens da Pós-modernidade: cultura, política e sociabilidade na América Latina (Itajaí: Univali, 2007). Suas linhas de pesquisa estão relacionadas a teorias sociais contemporâneas, movimentos sociais e culturais, política e sociedade latino-americana. 